\title{
Acute and chronic effects of taurine magnesium coordination compound on cardiac sodium channel Nav1.5
}

\author{
LIN ZHAO $^{1}$, XIAO-XU YANG ${ }^{2}$, YONG-QIANG YIN ${ }^{3}$, HONG WU $^{3,4}$, YI KANG ${ }^{3}$ and JIAN-SHI LOU ${ }^{3}$ \\ ${ }^{1}$ International Medical School, Tianjin Medical University; ${ }^{2}$ Department of Pharmacy, Tianjin Medical University \\ Metabolic Disease Hospital; ${ }^{3}$ Department of Pharmacology, Tianjin Medical University, Tianjin 300070; \\ ${ }^{4}$ Department of Pharmacology, Mudanjiang Medical University, Mudanjiang, Heilongjiang 157011, P.R. China
}

Received June 13, 2016; Accepted April 12, 2017

DOI: $10.3892 / \mathrm{mmr} .2017 .7117$

\begin{abstract}
It has been previously demonstrated that taurine magnesium coordination compound (TMCC) produces antiarrhythmic effects in vivo. The present study investigated the acute and chronic effect of TMCC on sodium channels in HEK cells stably expressing human cardiac Nav1.5 sodium channels. The current amplitude, activation and inactivation kinetics, recovery time from inactivation, and use-dependent block of sodium channels were analyzed using the whole-cell patch clamp technique. Western blotting was used to analyze Nav1.5 expression following chronic TMCC treatment. In HEK cells expressing Nav1.5 channels, TMCC acutely inhibited $\mathrm{Na}^{+}$currents in a dose-dependent manner. In addition, acute application of TMCC shifted the activation and inactivation curves, and prolonged the recovery time from inactivation, but did not exhibit a use-dependent block of Nav1.5. By contrast, chronic TMCC treatment only produced a use-dependent block of Nav1.5 and downregulated Nav1.5 expression. The results of the present study suggested that TMCC may produce antiarrhythmic actions via acute inhibition of sodium channel currents and chronic downregulation of Nav1.5 expression.
\end{abstract}

\section{Introduction}

Voltage-gated $\mathrm{Na}^{+}$channels are essential for the generation and propagation of action potentials in many excitable cells, including cardiac myocytes and neurons. Nav1.5, the cardiac isoform of the voltage-gated $\mathrm{Na}^{+}$channel $\alpha$ subunit, serves an important role in cardiac electrophysiology, including initiation of the cardiac action potential, electrical impulse conduction and control of action potential duration (1). Nav1.5 mutations are associated with numerous types of arrhythmia,

Correspondence to: Dr Jian-Shi Lou, Department of Pharmacology, Tianjin Medical University, 22 Qixiangtai Road, Tianjin 300070, P.R. China

E-mail: alex_19840420@126.com

Key words: Nav1.5, sodium current, taurine magnesium coordination compound, arrhythmia, $\mathrm{IC}_{50}$, HEK cells, whole-cell patch clamp technique including congenital long QT syndrome type 3, progressive cardiac conduction defect, Brugada syndrome, idiopathic ventricular fibrillation, sick sinus syndrome and familial atrial fibrillation $(2,3)$. In addition, Nav1.5 is the primary target for class 1 antiarrhythmic drugs (4). Inhibition of sodium channels by class 1 antiarrhythmic drugs decreases the initial depolarization of the action potential and slows the propagation of the electrical impulse, thereby alleviating arrhythmias. Identification of novel drugs that target Nav1.5 may be a therapeutic strategy for the treatment of cardiac arrhythmia.

Preclinical and clinical studies have demonstrated that taurine and magnesium prevent arrhythmias and produce cardioprotective effects (5-8). Previous studies synthesized a taurine-magnesium coordination compound (TMCC), and demonstrated that TMCC is able to effectively block arrhythmias induced by electrical stimulation, epinephrine, aconitine, stophanthin $\mathrm{G}$ and cesium chloride in vivo (9-11). TMCC inhibits sodium currents and transient outward potassium currents, and moderately stimulates L-type calcium channels in rat ventricular myocytes $(9,11)$. In addition, it was previously observed that TMCC attenuates ion channel dysfunction induced by hypoxia/reoxygenation and ouabain in rat ventricular myocytes $(9,10)$. These previous results suggest that TMCC may be a novel antiarrhythmic drug, targeting sodium, potassium and calcium channels.

During depolarization, $\mathrm{Na}^{+}$channels undergo conformational transitions from the resting state to the open state, and subsequently to the inactivated state (12). It is well-known that a number of antiarrhythmic drugs, including lidocaine, exert a state- and use-dependent inhibition of sodium channels (13). Although it has been previously demonstrated that TMCC inhibits sodium currents in rat ventricular myocytes, it remains unclear how TMCC modulates different states of cardiac sodium channels. In addition, TMCC inhibits $\mathrm{Na}^{+}$ channels in rat ventricular myocytes $(9,10)$. However, it is unclear whether TMCC produces a similar effect in human $\mathrm{Na}^{+}$channels, particularly the cardiac Nav1.5 channel.

In the present study, the inhibitory effect of TMCC on human cardiac Nav1.5 channels was investigated using HEK cells stably expressing Nav1.5. In addition, the chronic effect of TMCC on human Nav1.5 was investigated, and the possible mechanisms underlying the chronic effect of TMCC on human Nav1.5 were examined. 


\section{Materials and methods}

Cell culture. HEK-293 cells (ICE-Bioscience Co., Ltd., Beijing, China) stably expressing Nav1.5 $\mathrm{Na}^{+}$channels were cultured in Dulbecco's modified Eagle's medium (Gibco; Thermo Fisher Scientific, Inc., Waltham, MA, USA) supplemented with $10 \%$ fetal bovine serum (Gibco; Thermo Fisher Scientific, Inc.) and $200 \mu \mathrm{g} / \mathrm{ml} \mathrm{G} 418$ (Amresco, LLC, Solon, OH, USA) at $37^{\circ} \mathrm{C}$ in a humidified incubator with $5 \% \mathrm{CO}_{2}$. Cells were harvested with $0.25 \%$ trypsin-EGTA solution when the cells reached $70-80 \%$ confluence. Single cells were used for the electrophysiological experiments.

Electrophysiology. HEK cells stably expressing Nav1.5 were placed into a perfusion chamber set on the stage of an inverted microscope (Olympus IX51; Olympus Corporation, Tokyo, Japan). The electrophysiological recordings were performed in the whole-cell configuration. The patch pipettes were of 2-4 $\mathrm{m} \Omega$ resistance. Data were acquired using an Axopatch 700B amplifier controlled by Clampex software (version 10.0) via a Digidata 1440 analogue-to-digital converter(all Molecular Devices, LLC, Sunnyvale, CA, USA). The whole-cell series resistance was compensated to $>80 \%$. The standard external solution contained: $120 \mathrm{mM}$ choline chloride; $25 \mathrm{mM} \mathrm{NaCl}$; $4 \mathrm{mM} \mathrm{CsOH} ; 0.1 \mathrm{mM} \mathrm{CaCl}_{2} ; 2 \mathrm{mM} \mathrm{CoCl} \mathrm{Cl}_{2} ; 1 \mathrm{mM} \mathrm{MgCl}$; $10 \mathrm{mM}$ HEPES; and $10 \mathrm{mM}$ glucose, at $\mathrm{pH}$ 7.4, adjusted with $\mathrm{KOH}$. The pipette solution contained: $140 \mathrm{mM} \mathrm{CsCl} ; 10 \mathrm{mM}$ $\mathrm{NaCl} ; 5 \mathrm{mM}$ EGTA; $5 \mathrm{mM}$ HEPES; and $5 \mathrm{mM} \mathrm{Na}_{2}$ ATP, at $\mathrm{pH}$ 7.3, adjusted with CsOH. TMCC in the external solution was added 5 min after whole-cell configuration was formed. In order to measure the $\mathrm{Na}^{+}$current amplitude, cells were held at a holding potential of $-100 \mathrm{mV}$, and voltage clamped with voltage steps from -90 to $+25 \mathrm{mV}$ in $5-\mathrm{mV}$ increments. The sodium current $\left(\mathrm{I}_{\mathrm{Na}}\right)$ was calculated as the difference between the peak current and the holding current level. Steady-state activation curves were obtained from the current-voltage characteristic and fitted to the Boltzmann equation as follows: $\mathrm{G} / \mathrm{Gmax}=1 /\left[1+\exp \left(\mathrm{V}-\mathrm{V}_{1 / 2}\right) / \mathrm{k}\right]$; where $\mathrm{G}$ is the conduction, $\mathrm{V}_{1 / 2}$ is the voltage of half-maximal activation and $\mathrm{k}$ is a slope factor. The voltage-dependent steady-state inactivation of $\mathrm{I}_{\mathrm{Na}}$ was determined by applying $50 \mathrm{msec}$ voltage steps from -150 to $-30 \mathrm{mV}$ in $10 \mathrm{mV}$ increments, followed by a $25 \mathrm{msec}$ test pulse at $-30 \mathrm{mV}$. The data were fitted to the Boltzmann equation as follows: $\mathrm{I} / \mathrm{Imax}=1 /\left[1+\exp \left(\mathrm{V}-\mathrm{V}_{1 / 2}\right) / \mathrm{k}\right]$; where $\mathrm{V}_{1 / 2}$ is the voltage of half-maximal inactivation and $\mathrm{k}$ is the slope factor. A two-pulse (pre-pulse and test pulse) protocol was used to study the recovery of Nav1.5 channels from inactivation. $\mathrm{I}_{\mathrm{Na}}$ was elicited by a $30 \mathrm{msec}$ pre-pulse from -90 to $-40 \mathrm{mV}$, followed by a $30 \mathrm{msec}$ test pulse from -90 to $-40 \mathrm{mV}$ from a holding potential of $-90 \mathrm{mV}$. The use-dependent properties of Nav1.5 channels were tested by repetitive pulses of $-40 \mathrm{mV}$ for $10 \mathrm{msec}$ from a holding potential of $-100 \mathrm{mV}$, applied at 1,3 and $10 \mathrm{~Hz}$ for a total of 100 pulses.

Western blotting. Following treatment with $10,100 \mu \mathrm{M}$ and $1 \mathrm{mM}$ TMCC (synthesized in the laboratory of the present study) at $37^{\circ} \mathrm{C}$ for $24 \mathrm{~h}$, HEK cells stably expressing Nav1.5 $\mathrm{Na}^{+}$ channels were homogenized in lysis buffer containing $20 \mathrm{mM}$ Tris (pH 7.5), $150 \mathrm{mM} \mathrm{NaCl}, 1 \%$ Triton X-100, sodium pyrophosphate, $\beta$-glycerophosphate, EDTA, $\mathrm{Na}_{3} \mathrm{VO}_{4}$, and leupeptin
Table I. Effects of TMCC on peak $\mathrm{I}_{\mathrm{Na}}$ in HEK-293 cells stably expressing Nav1.5 channels.

\begin{tabular}{lc} 
TMCC concentration & Inhibition, \% \\
\hline $1 \mu \mathrm{M}$ & $14.13 \pm 0.47$ \\
$10 \mu \mathrm{M}$ & $22.65 \pm 1.14$ \\
$100 \mu \mathrm{M}$ & $31.57 \pm 3.22$ \\
$1 \mu \mathrm{M}$ & $34.67 \pm 4.41$ \\
$10 \mu \mathrm{M}$ & $41.45 \pm 2.76$ \\
\hline
\end{tabular}

Data are presented as the mean \pm standard error of the mean. TMCC, taurine magnesium coordination compound; $\mathrm{I}_{\mathrm{Na}}$, Na current.

(Beyotime Institute of Biotechnology, Haimen, China) for $30 \mathrm{~min}$ on ice. The lysates were centrifuged at $12,000 \mathrm{x} \mathrm{g}$ at $4^{\circ} \mathrm{C}$ for $15 \mathrm{~min}$. Protein concentrations were determined using the Bradford method. Proteins $(50 \mu \mathrm{g})$ were separated using SDS-PAGE on a $6 \%$ gel and transferred onto polyvinylidene fluoride membranes by electroblotting. Membranes were incubated with primary antibodies against Nav1.5 channel (rabbit anti-human Nav1.5; 1:200; cat. no. H0912; Santa Cruz Biotechnology, Inc., Dallas, TX, USA) at $4^{\circ} \mathrm{C}$ overnight. $\beta$-actin (1:500; cat. no. L2812, Santa Cruz Biotechnology, Inc.) was used as a loading control. Membranes were subsequently incubated with horseradish peroxidase-conjugated goat anti-rabbit secondary antibodies (1:10,000, cat. no. 074-1506; KPL, Inc., Gaithersburg, MD, USA) at room temperature for $1 \mathrm{~h}$. Bands were visualized using an enhanced chemiluminescence kit (Beyotime Institute of Biotechnology) by exposure to Kodak $\mathrm{X}$-ray film. Results was analyzed using Image J software, version 1.48 (National Institutes of Health, Bethesda, MD, USA).

Statistical analysis. Data are presented as the mean \pm standard error. Curves were fitted using Clampfit software (version 10.0; Molecular Devices, LLC), and the calculations and graphical presentations were generated using Origin software (version 6.0; OriginLab Corporation, Northampton, MA, USA). Statistical analyses were performed using SPSS software (version 13.0, SPSS Inc., Chicago, IL, USA). One-way analysis of variance was used to compare the difference among groups, followed by post hoc univariate analysis of variance between groups tests. Paired t-tests were used to compare the differences prior to and following treatment within a group. $\mathrm{P}<0.05$ was considered to indicate a statistically significant difference.

\section{Results}

TMCC inhibits cardiac sodium channel Nav1.5 expressed in a stable cell line. The sodium channel Nav1.5 is primarily expressed in cardiac muscles and Nav1.5 mutations are associated with cardiac arrhythmia (14). The present study analyzed the effect of TMCC on the cardiac sodium channel Nav1.5 in HEK cells stably expressing Nav1.5. TMCC (between $1 \mu \mathrm{M}$ and $10 \mathrm{mM}$ ) inhibited sodium currents in HEK cells in a dose-dependent manner (Fig. 1A). Treatment with TMCC at 1, 10 and $100 \mu \mathrm{M}$, and 1 and $10 \mathrm{mM}$ concentrations inhibited the peak currents of Nav1.5 channels by $14.13 \pm 0.47,22.65 \pm 1.14$, 
A

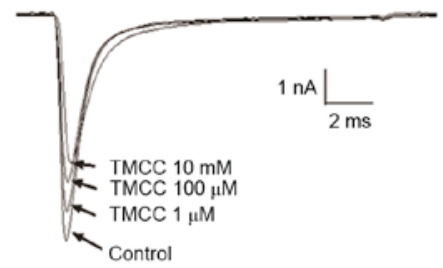

D

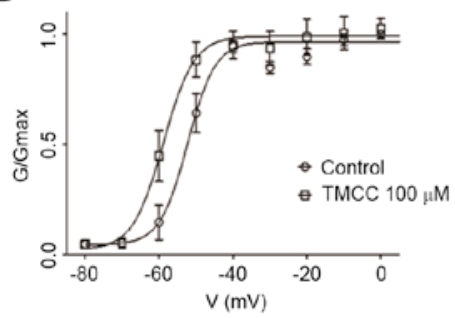

B

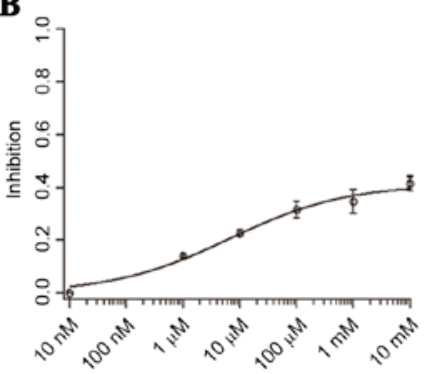

E

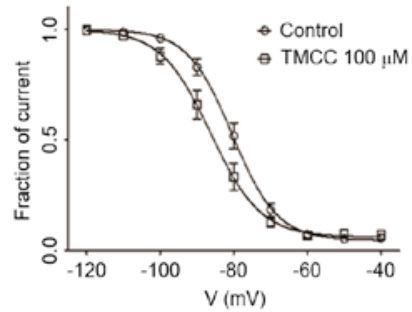

C

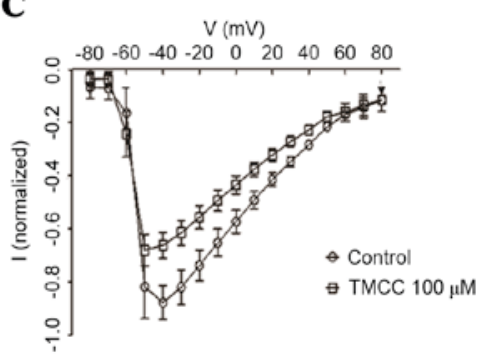

F

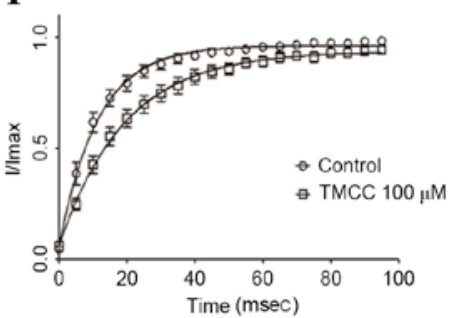

Figure 1. Effect of TMCC on Nav1.5 sodium currents in HEK cells stably expressing Nav1.5 channels. (A) Representative traces of $\mathrm{I}_{\mathrm{Na}}$ at -40 mV recorded from control cells, and cells treated with 1, $100 \mu \mathrm{M}$, and $10 \mathrm{mM}$ TMCC. (B) The inhibition of peak currents at various concentrations of TMCC was used to plot the dose-response curve. The plot was fitted to Hill equations. The $\mathrm{IC}_{50}$ of $\mathrm{TMCC}$ was $8.1 \pm 0.5 \mu \mathrm{M}$. (C) $\mathrm{I} / \mathrm{V}$ measurements of $\mathrm{I}_{\mathrm{Na}}$ recorded in control cells and cells treated with $100 \mu \mathrm{M}$ TMCC. (D) The steady-state activation and (E) inactivation of Nav1.5 sodium channels in control cells and cells treated with $100 \mu \mathrm{M}$ TMCC. (F) The recovery from inactivation of $\mathrm{I}_{\mathrm{Na}}$ elicited by a $30 \mathrm{msec}$ pre-pulse from -90 to $-40 \mathrm{mV}$, followed by a $30 \mathrm{msec}$ test pulse from -90 to $-40 \mathrm{mV}$ from a holding potential of $-90 \mathrm{mV}$. The two pulse protocol was repeated by varying the interval between two pulses from 5 to $100 \mathrm{msec}$ in $5 \mathrm{msec}$ increments. The fractional current measured by $\mathrm{I}_{\text {test }} / \mathrm{I}_{\text {pre-pulse }}$ was plotted against the pulse interval, and fitted to a single exponential function. TMCC, taurine magnesium coordination compound; $\mathrm{I}_{\mathrm{Na}}$, Na current.

$31.57 \pm 3.22,34.67 \pm 4.41$ and $41.45 \pm 2.76 \%$, respectively (Fig. $1 \mathrm{~A}$ Table I). The inhibition of peak currents at various concentrations of TMCC was used to generate the dose-response curve (Fig. 1B). I/V curves demonstrated that TMCC $(100 \mu \mathrm{M})$ inhibited Nav1.5 currents across the range of tested voltages, with the maximum inhibition at $-40 \mathrm{mV}$ (Fig. 1C). The half activation potential was shifted from $-52.27 \pm 1.1 \mathrm{mV}$ in control cells to $-58.83 \pm 0.59 \mathrm{mV}$ in cells treated with $100 \mu \mathrm{M}$ TMCC ( $n=6$; Fig. 1D). The slope factor $\mathrm{k}$ was not notably altered between the control group and the TMCC-treated group. In addition, the half inactivation potential was shifted from $-80.38 \pm 0.20 \mathrm{mV}$ in control cells to $-86.28 \pm 0.27 \mathrm{mV}$ in cells treated with $100 \mu \mathrm{M}$ TMCC (Fig. 1E).

The effect of TMCC on the recovery of Nav1.5 channel from inactivation was subsequently investigated. A two-pulse (pre-pulse and test pulse) protocol was used for the recovery experiment. The two-pulse protocol was repeated by varying the interval between the two pulses from 5 to $100 \mathrm{msec}$ in $5 \mathrm{msec}$ increments. The fractional current measured by $\mathrm{I}_{\text {test }} / \mathrm{I}_{\text {pre-pulse }}$ was plotted against the pulse interval, and fitted to a single exponential function (Fig. 1F). The recovery time constant was $11.43 \pm 0.17 \mathrm{msec}$ for the control group and $19.28 \pm 1.15 \mathrm{msec}$ for the TMCC-treated group $(n=6)$.

The use-dependent phenotype of Nav1.5 channels in the presence of $100 \mu \mathrm{M}$ TMCC was subsequently assessed. TMCC did not significantly block peak currents during repetitive pulses of $-40 \mathrm{mV}$ for $10 \mathrm{msec}$ from a holding potential of $-100 \mathrm{mV}$, applied at 1,3 and $10 \mathrm{~Hz}$ for a total of 100 pulses (Fig. 2).

Chronic effects of TMCC on Navl.5 sodium channels expressed in a stable cell line. The present study investigated the chronic effect of TMCC on Nav1.5 sodium channels in HEK cells expressing Nav1.5 channels. The current density at $-40 \mathrm{mV}$ was $-285.61 \pm 28.92 \mathrm{pA} / \mathrm{pF}$ in control cells and $-226.7 \pm 24.13 \mathrm{pA} / \mathrm{pF}$ in Nav1.5-expressing HEK cells treated with $100 \mu \mathrm{M}$ TMCC for $24 \mathrm{~h}$ (Fig. 3A). Although the current density of $\mathrm{I}_{\mathrm{Na}}$ in TMCC-treated cells exhibited a tendency toward attenuated currents compared with control cells, no statistically significant difference was observed. There was no obvious shift of $\mathrm{I} / \mathrm{V}$ curves of $\mathrm{I}_{\mathrm{Na}}$ between the control group and the TMCC-treated group (Fig. 3A). The half activation potential was $-51.22 \pm 0.82 \mathrm{mV}$ in the control group and $-53.16 \pm 0.99 \mathrm{mV}$ in the TMCC-treated group, and the slope factor $\mathrm{k}$ was $2.69 \pm 1.17$ in the control group and 3.28 \pm 0.74 in the TMCC-treated group. There was no notable difference in the half activation potential and the slope factor $\mathrm{k}$ between the control group and the TMCC-treated group (Fig. 3B). In addition, there was no notable difference in the half activation potential and the slope factor $\mathrm{k}$ between the control group $\left(\mathrm{V}_{1 / 2}=-72.06 \pm 0.39 \mathrm{mV} ; \mathrm{k}=5.50 \pm 0.35\right)$ and the TMCC-treated group $\left(\mathrm{V}_{1 / 2}=-73.67 \pm 0.35 \mathrm{mV} ; \mathrm{k}=5.46 \pm 0.31\right)$ (Fig. 3C). The recovery time constant was not altered between the control group $(6.38 \pm 0.22 \mathrm{msec})$ and the TMCC-treated group (7.08 $\pm 0.95 \mathrm{msec}$ ) (Fig. 3D). Treatment with $100 \mu \mathrm{M}$ TMCC for $24 \mathrm{~h}$ significantly blocked peak currents during repetitive pulses of $-40 \mathrm{mV}$ for $10 \mathrm{msec}$, from a holding potential of $-100 \mathrm{mV}$ applied at $10 \mathrm{~Hz}$, although not 1 or $3 \mathrm{~Hz}$, for a total of 100 pulses (Fig. 4).

Using western blotting, the chronic effect of TMCC on Nav1.5 expression in HEK cells stably expressing Nav1.5 channels was further analyzed. Treatment with TMCC $(10,100 \mu \mathrm{M}$ and $1 \mathrm{mM})$ for $24 \mathrm{~h}$ significantly decreased Nav1.5 expression ( $\mathrm{P}<0.05$ vs. control; Fig. 5). 
$\mathbf{A}$

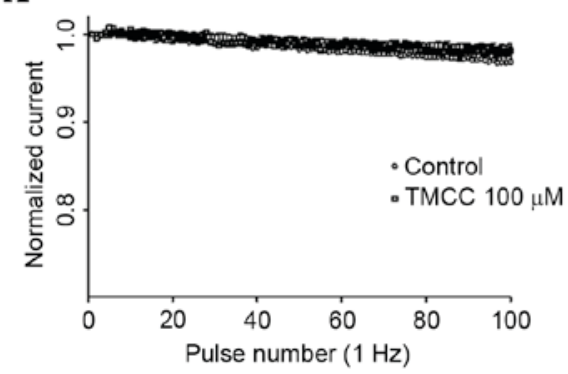

C

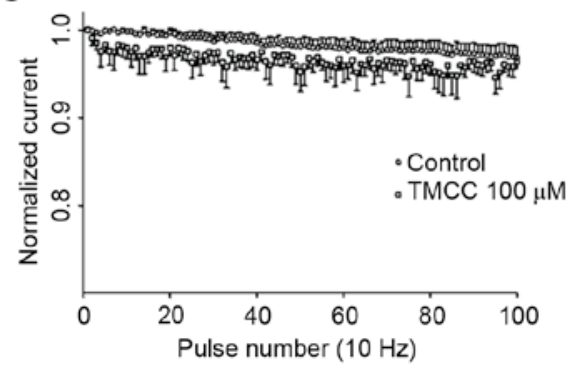

B

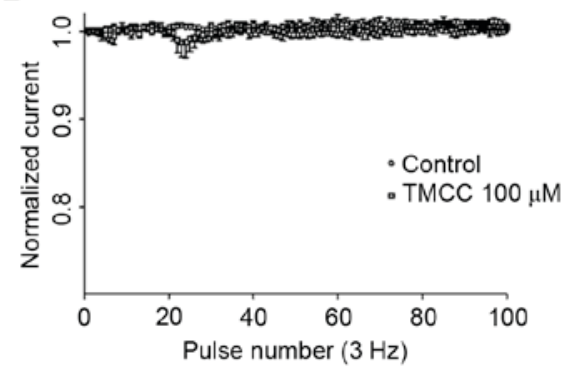

D

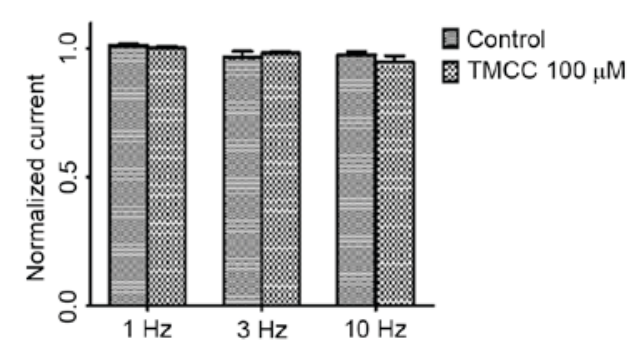

Figure 2. TMCC does not exhibit use-dependent inhibition of Nav1.5 sodium channels. Na current recorded from control cells and cells treated with $100 \mu \mathrm{M}$ TMCC was elicited by repetitive pulses at $-40 \mathrm{mV}$ for $10 \mathrm{msec}$ from a holding potential of $-100 \mathrm{mV}$, applied at (A) 1 , (B) 3 and (C) $10 \mathrm{~Hz}$ for a total of $100 \mathrm{pulses}$. Peak currents were measured, normalized to the initial peak current amplitude and plotted against the corresponding pulse. The curve was fitted to a single exponential function. (D) Results of quantification. $\mathrm{n}=6$. TMCC, taurine magnesium coordination compound.

$\mathbf{A}$

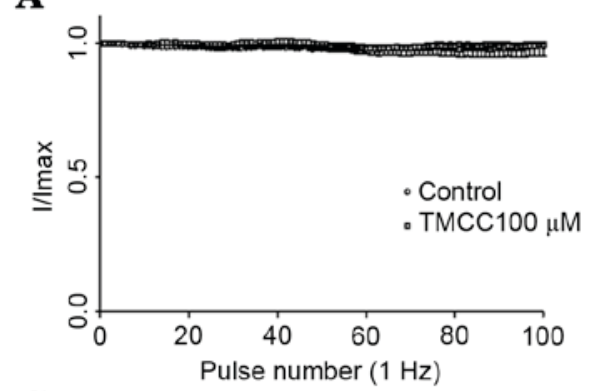

C

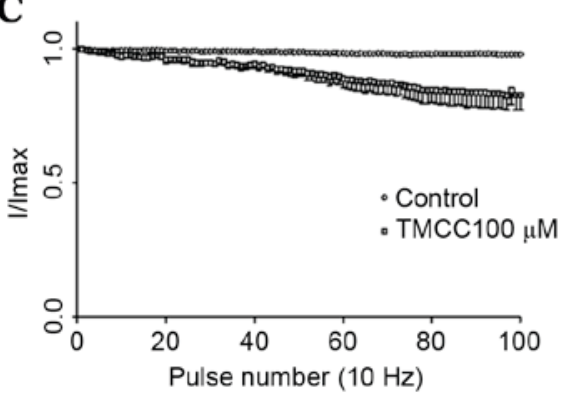

B

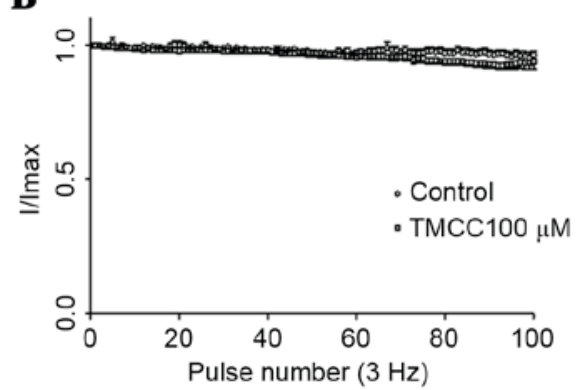

D

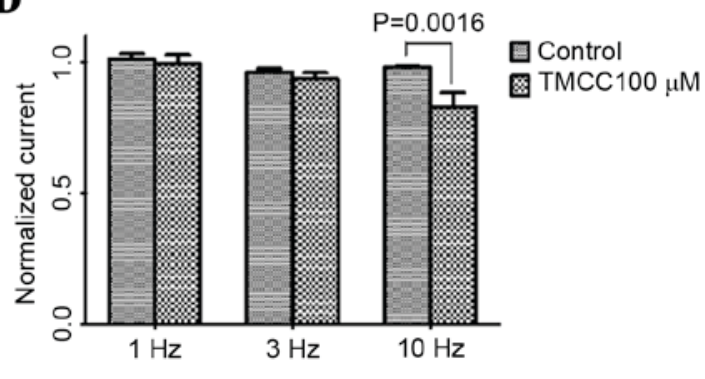

Figure 3. Chronic effect of TMCC on the Nav1.5 sodium channel in HEK cells stably expressing Nav1.5 channels. (A) I/V measurements of $\mathrm{I}_{\mathrm{Na}}$ recorded in control cells and cells treated with $100 \mu \mathrm{M}$ TMCC for $24 \mathrm{~h}$. (B) The steady-state activation and (C) inactivation of Nav1.5 sodium channels in control cells and cells treated with $100 \mu \mathrm{M} \mathrm{TMCC}$ for $24 \mathrm{~h}$. (D) The recovery from inactivation of $\mathrm{I}_{\mathrm{Na}}$ recorded in control cells and cells treated with $100 \mu \mathrm{M}$ TMCC for $24 \mathrm{~h}$. $\mathrm{n}=6$. TMCC, taurine magnesium coordination compound; $\mathrm{I}_{\mathrm{Na}}$, Na current.

\section{Discussion}

It has been previously demonstrated that TMCC produces antiarrhythmic effects (9-11). Previous studies have suggested that the inhibition of sodium channels by TMCC contributes to the antiarrhythmic effect (11); however, the antiarrhythmic mechanisms associated with TMCC remain to be completely elucidated. In the present study, the effect of TMCC on the human cardiac sodium channel Nav1.5 was analyzed in HEK cells stably expressing Nav1.5 channels. It was observed that TMCC inhibited Nav1.5 currents in a dose- and voltage-dependent manner. The inhibition of Nav1.5 currents exhibited no use-dependence when TMCC was applied acutely, although the inhibition was use-dependent when TMCC was applied chronically. Additionally, chronic treatment with TMCC downregulated Nav1.5 expression. The results of the present 
$\mathbf{A}$

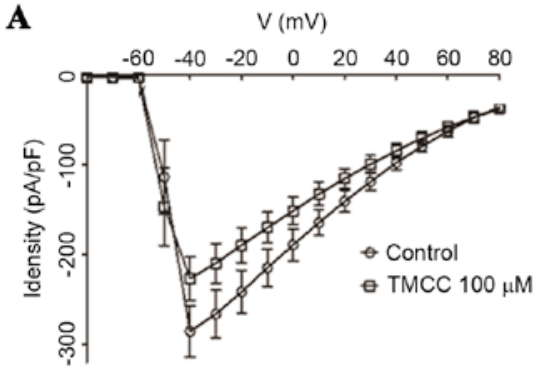

C

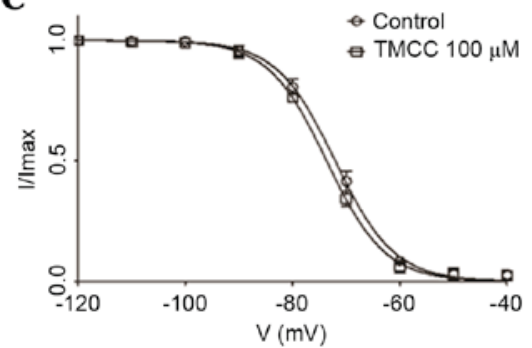

B

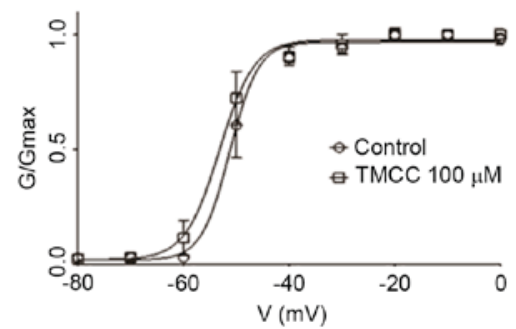

D

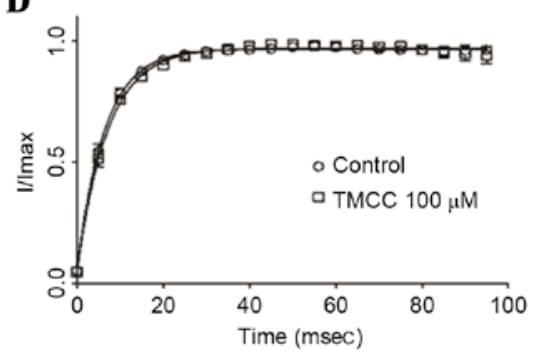

Figure 4. TMCC exhibits a use-dependent inhibition of Nav1.5 sodium channels. A-C. Na current at (A) 1, (B) 3 and (C) $10 \mathrm{~Hz}$ recorded from control cells and cells treated with $100 \mu \mathrm{M}$ TMCC for $24 \mathrm{~h}$. (D) Results of quantification. $\mathrm{n}=6$. TMCC, taurine magnesium coordination compound.

$\mathbf{A}$

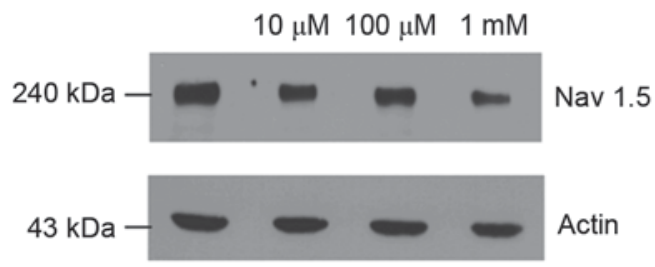

B

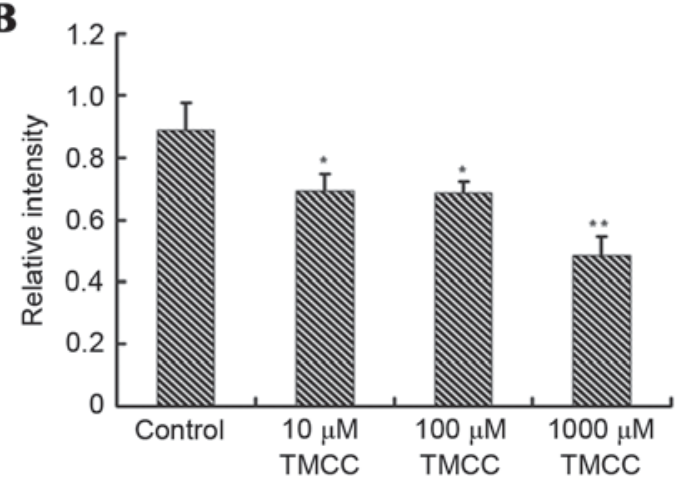

Figure 5. TMCC inhibits Nav1.5 expression in HEK cells stably expressing Nav1.5 channels. (A) Representative western blot analysis exhibiting Nav1.5 expression in control cells and cells treated with $10,100 \mu \mathrm{M}$, and $1 \mathrm{mM} \mathrm{TMCC}$ for $24 \mathrm{~h}$. $\beta$-actin was used as a loading control. (B) Quantification of Nav1.5 expression normalized to $\beta$-actin. $\mathrm{n}=6 .{ }^{*} \mathrm{P}<0.05,{ }^{* *} \mathrm{P}<0.01$ vs. control. TMCC, taurine magnesium coordination compound.

study demonstrated that TMCC may produce its antiarrhythmic effect via inhibition of Nav1.5 sodium currents and downregulation of Nav1.5 expression.

The voltage-gated $\mathrm{Na}^{+}$channel is important for the excitability of cardiac ventricular myocytes, and is a primary target for class 1 antiarrhythmic agents, including quinidine, lidocaine, and phenytoin (15). It was previously observed that TMCC inhibited $\mathrm{I}_{\mathrm{Na}}$ currents, and prevented arrhythmias induced by electrical stimulation, epinephrine, aconitine, stophanthin $\mathrm{G}$ and cesium chloride (9-11). Therefore, inhibition of sodium channels by TMCC may contribute to its antiarrhythmic action. Nav1.5 has been demonstrated to be the cardiac isoform of the voltage $\alpha$ subunit, which forms the ion-conducting pore (16). In the present study, it was observed that acute application of TMCC inhibited Nav1.5 currents in a dose-dependent manner. However, TMCC at a concentration of $10 \mathrm{mM}$ only inhibited $\sim 40 \%$ of sodium currents, suggesting that TMCC is a moderate sodium channel inhibitor. In addition, it was demonstrated that TMCC shifted the activation curve of Nav1.5 currents to the left, suggesting that TMCC may bind to the activated state of Nav1.5 and facilitate the opening of the channel. TMCC additionally shifted the inactivation curve of Nav1.5 currents to the left, suggesting that TMCC may promote inactivation of the channel. Therefore, the primary blocking effect of TMCC on Nav1.5 currents may be caused by accelerating the inactivation of Nav1.5 channels. The results of the present study demonstrated that the recovery time of Nav1.5 channels from inactivation was prolonged following acute application of TMCC, strengthening the hypothesis that TMCC acts primarily on the inactivated state of the Nav1.5 channel.

In contrast to the acute effect of TMCC, it was observed that chronic treatment with TMCC did not significantly inhibit Nav1.5 currents, shift the activation and inactivation curves, or prolong the recovery time from inactivation. The results of the present study suggested that chronic TMCC treatment did not significantly alter Nav1.5 channel kinetics. However, it was observed that chronic, and not acute, application of TMCC exhibited a use-dependent blockade of Nav1.5. It is well-known that certain antiarrhythmic agents, including 
lidocaine, block sodium channels in a use-dependent (also termed frequency-dependent) manner (17). This use-dependent blockade of sodium channels renders the drug a more potent blocker when sodium channels are activated with a higher frequency in disease states, including arrhythmia. Therefore, the results of the present study, demonstrating that chronic treatment with TMCC may produce a use-dependent block of the Nav1.5 channel, suggest that TMCC may produce a more potent antiarrhythmic effect when used for a prolonged period.

In addition to the use-dependent inhibition of Nav1.5 channels, chronic treatment with TMCC resulted in a significant decrease in Nav1.5 expression. It has been reported that certain drugs, including arsenic trioxide, prolong action potential duration and QT interval by inhibiting potassium channel expression $(18,19)$. In addition, class I antiarrhythmic agents have been reported to upregulate cardiac $\mathrm{Na}^{+}$channel expression, which is believed to cause arrhythmias secondary to the therapy $(20,21)$. Therefore, inhibition of Nav1.5 expression may be a therapeutic strategy for the treatment of arrhythmias (22). The results of the present study, demonstrating that chronic treatment with TMCC inhibited Nav1.5 expression, suggest that TMCC may produce antiarrhythmic effects via downregulation of Nav1.5 expression.

In conclusion, the present study investigated the acute and chronic effect of TMCC on sodium channels in HEK cells expressing human cardiac Nav1.5 channels. It was observed that acute application of TMCC inhibited Nav1.5 currents, shifted the activation and inactivation curves, and prolonged the recovery time from inactivation in HEK cells expressing Nav1.5 channels. By contrast, chronic treatment with TMCC resulted in a use-dependent block of Nav1.5 channels and a downregulation of Nav1.5 expression. The results of the present study demonstrated that TMCC may produce antiarrhythmic actions via acute inhibition of sodium channels and chronic downregulation of Nav1.5 expression.

\section{Acknowledgements}

The present study was supported by the National Natural Science Foundation of China (grant no. 81373410) and the China Postdoctoral Science Foundation (grant nos. 2014M561196, 2016T90211).

\section{References}

1. Nerbonne JM and Kass RS: Molecular physiology of cardiac repolarization. Physiol Rev 85: 1205-1253, 2005.

2. Adsit GS, Vaidyanathan R, Galler CM, Kyle JW and Makielski JC: Channelopathies from mutations in the cardiac sodium channel protein complex. J Mol Cell Cardiol 61: 34-43, 2013.

3. Ruan Y, Liu N and Priori SG: Sodium channel mutations and arrhythmias. Nat Rev Cardiol 6: 337-348, 2009.
4. Roden DM: Pharmacology and toxicology of Nav1.5-Class 1 anti-arrhythmic drugs. Card Electrophysiol Clin 6: 695-704, 2014.

5. Hanna J, Chahine R, Aftimos G, Nader M, Mounayar A, Esseily $\mathrm{F}$ and Chamat $\mathrm{S}$ : Protective effect of taurine against free radicals damage in the rat myocardium. Exp Toxicol Pathol 56: 189-194, 2004.

6. Eby G and Halcomb WW: Elimination of cardiac arrhythmias using oral taurine with 1-arginine with case histories: Hypothesis for nitric oxide stabilization of the sinus node. Med Hypotheses 67: 1200-1204, 2006.

7. Brugada P: Magnesium: An antiarrhythmic drug, but only against very specific arrhythmias. Eur Heart J 21: 1116, 2000.

8. Coates BJ, Broderick TL, Batia LM and Standley CA: MgSO4 prevents left ventricular dysfunction in an animal model of preeclampsia. Am J Obstet Gynecol 195: 1398-1403, 2006.

9. Zhao L, Lou J, Wu H, Yin Y and Kang Y: Effects of taurine-magnesium coordination compound on ionic channels in rat ventricular myocytes of arrhythmia induced by ouabain. Biol Trace Elem Res 147: 275-284, 2012.

10. Zhao L, Lou JS and Kang Y: Taurine-magnesium coordination compound attenuates hypoxia/reoxygenation induced ion channel dysfunction in rat ventricular myocytes. Drug Res (Stuttg) 63: 185-191, 2013.

11. Yin Y, Wen K, Wu Y, Kang Y and Lou J: Inhibition of sodium current by taurine magnesium coordination compound prevents cesium chloride-induced arrhythmias. Biol Trace Elem Res 146: 192-198, 2012.

12. Aldrich RW, Corey DP and Stevens CF: A reinterpretation of mammalian sodium channel gating based on single channel recording. Nature 306: 436-441, 1983.

13. Wang GK and Strichartz GR: State-dependent inhibition of sodium channels by local anesthetics: A 40-year evolution. Biochem (Mosc) Suppl Ser A Membr Cell Biol 6: 120-127, 2012.

14. Song W and Shou W: Cardiac sodium channel Nav1.5 mutations and cardiac arrhythmia. Pediatr Cardiol 33: 943-949, 2012.

15. Kowey PR: Pharmacological effects of antiarrhythmic drugs. Review and update. Arch Intern Med 158: 325-332, 1998.

16. Grant AO: Cardiac ion channels. Circ Arrhythm Electrophysiol 2: 185-194, 2009.

17. Makielski JC, Alpert LA and Hanck DA: Two components of use-dependent block of sodium current by lidocaine in voltage clamped cardiac Purkinje cells. J Mol Cell Cardiol 23 (Suppl 1): S95-S102, 1991.

18. Ficker E, Kuryshev YA, Dennis AT, Obejero-Paz C, Wang L, Hawryluk P, Wible BA and Brown AM: Mechanisms of arsenic-induced prolongation of cardiac repolarization. Mol Pharmacol 66: 33-44, 2004.

19. Cordes JS, Sun Z, Lloyd DB, Bradley JA, Opsahl AC, Tengowski MW, Chen X and Zhou J: Pentamidine reduces hERG expression to prolong the QT interval. Br J Pharmacol 145: 15-23, 2005.

20. Taouis M, Sheldon RS and Duff HJ: Upregulation of the rat cardiac sodium channel by in vivo treatment with a class I antiarrhythmic drug. J Clin Invest 88: 375-378, 1991.

21. Duff HJ, Offord J, West J and Catterall WA: Class I and IV antiarrhythmic drugs and cytosolic calcium regulate mRNA encoding the sodium channel alpha subunit in rat cardiac muscle. Mol Pharmacol 42: 570-574, 1992.

22. Rook MB, Evers MM, Vos MA and Bierhuizen MF: Biology of cardiac sodium channel Nav1.5 expression. Cardiovasc Res 93: 12-23, 2012. 